\title{
Risk Factors for Diabetic Retinopathy in Type 2 Diabetes Mellitus
}

\author{
Ali Nasir Sattar, FICMS* \\ Diabetes Clinic, Al-Hindeya General Hospital, Karbala, Iraq \\ Hussain Ali Tufaili, MRCS \\ Department of Ophthalmology, Al-Hindeya General Hospital, Karbala, Iraq
}

\begin{abstract}
Objectives: To find risk factors to diabetic retinopathy (DR) in type 2 diabetes mellitus (T2DM) patients.Methods: A four years cross sectional study involving 386 patients with T2DM conducted at the diabetes clinic in Al-Hindeya General Hospital, Karbala, Iraq. Interviews were done for the participants focused on sociodemographic factors and included general examination with laboratory screening for fasting blood glucose (FBG), glycated haemoglobin (HbA1c), and serum lipids. The participants underwent ophthalmological testing including visual acuity, slit lamp examination, and optical coherence tomography. The patients were divided into retinopathy and non-retinopathy groups involving 109 and 277 patients, respectively. Both groups were screened for risk factors including age, gender, duration of disease, body mass index (BMI), treatment modality, HbA1c, and dyslipidemia. Results: The study included 109 patients (62 females, 47 males) with retinopathy and 277 patients (149 females, 128 males) control. Mean age for retinopathy and control groups were $54.76 \pm 7.63$ and $54.15 \pm 9.20$ years, respectively. Mean duration of disease for retinopathy and control groups were $12.79 \pm 5.91$ and $8.51 \pm 5.16$ years, respectively. Longer duration of disease and poor glycemic control showed positive association with DR with a P-value of 0.0001 and 0.033 , respectively. Gender, BMI, age, treatment modality, and dyslipidemia showed negative association with DR.Conclusions: In our study DR significantly associated with longer duration of disease and poor glycemic control while the relation was insignificant for gender, BMI, age, treatment modality, and dyslipidemia.
\end{abstract}

Keywords: Type 2 diabetes mellitus, Diabetic retinopathy, glycated hemoglobin, risk factor for retinopathy.

DOI: $10.7176 / \mathrm{JHMN} / 70-08$

Publication date: January $31^{\text {st }} 2020$

\section{Introduction}

T2DM is a worldwide major health problem with multi-systemic involvement. Diabetes is expected to follow the projected increase in the global number of diabetics reaching 629 million by 2045. Such a huge number of patients supposed to associate with a wide range of complications including retinopathy (1).

DR Retinopathy is a well-recognized irreversible microvascular complication of long-standing DM with a variable prevalence in T2DM (2-5). Vision loss due to DR is now the main cause of blindness in developed countries as the prevalence of etiologies like glaucoma and cataract fell down as a result of implementing screening programs and the advancement is surgical techniques (6). It is estimated that $50 \%$ of the high-risk diabetic population are unaware of the presence of DR due to the subtle and progressive clinical features of early DR. This fact contributed to the increase visual morbidity in diabetic patients $(7,8)$.

Risk factors associated with DR had been studied in different geographical areas as an attempt to understand the behavior of the disease and implement programs for its prevention. Age, gender, duration of disease, BMI, treatment modality, HbAlc, and dyslipidemia were frequently screened in assessing DR (3, 9, 10, 11, 12). As with any other illness, modifying risk factors may well reduce the incidence and delay the progression of DR (8).

The study aims to detect risk factors associate with diabetic retinopathy in T2DM patients of the target population.

\section{Methodology}

Study design: A cross sectional study involving 386 patients (211 females and 175 males) with T2DM conducted from September 2015 to August 2019.

Study population: The participants were enrolled at the Diabetes Clinic in Al-Hindeya General Hospital, Kabala, Iraq. Following clinical assessment including ophthalmologic examination, the patients were divided in to two groups, namely, retinopathy group regardless of the grade (109 patients) and non-retinopathy group as control (277 patients). Both groups were age and gender matched with the same inclusion criteria

Inclusion and exclusion criteria: All participants were above 35 years of age and received treatment in the form oral anti-diabetes, insulin or mixed, with history of T2DM of more than 3 years.

Patients with non-DM retinal diseases, corneal disease and those with poor pupillary dilatation were excluded.

Participants screening: The participants had to complete a questionnaire about the socio-demographic criteria 
including age, gender, occupation, and catchment area. Detailed medical history was obtained including duration of disease, treatment modality, history of eye disease and hypertension.

A general clinical examination was performed on each individual and included blood pressure measurement in the sitting and standing positions using mercury sphygmomanometer. Anthropometric measurements including height and weight were estimated to calculate the BMI using the equation of weight in kilogram divided by height in squared meter. Then the patients were divided according to the BMI in to three groups as normal (BMI <24.9 kg/m2), overweight (BMI 25-29.9 kg/m2), and obese (BMI $>30 \mathrm{~kg} / \mathrm{m} 2)$ (13).

Glycemic control for each participant was decided by measuring fasting blood glucose and HbA1c. Fasting serum lipids were also measured. The fasting period was set at 12 hour. The patients were further assigned to three groups according to their HbA1c as: controlled $(<7 \%)$, borderline $(7-9 \%)$, and poor control $(>9 \%)$. The American diabetes association guidelines were used to define abnormal serum lipids as: total cholesterol (TC) $\geq$ $6.2 \mathrm{mmol} / \mathrm{L}$, low density lipoprotein $(\mathrm{LDL}-\mathrm{C}) \geq 2.6 \mathrm{mmol} / \mathrm{L}$, height density lipoprotein $(\mathrm{HDL}-\mathrm{C})<1.0 \mathrm{mmol} / \mathrm{L}$, and triglyceride $(\mathrm{TG}) \geq 1.7 \mathrm{mmol} / \mathrm{L}(14)$.

Chemistry analyzer (Cobas integra 400 plus, Roche Diagnostics, Germany) was used for HbA1c and lipid assays, the former done with $2 \mathrm{ml}$ of whole blood by immunoassay, while the latter done with $1 \mathrm{ml}$ of serum by photometric transmission measurement.

All participants verbally consented to share their data in this study.

Eye examination and retinopathy grading: Initial visual acuity, intraocular pressure measurement, refraction followed by slit lamp examination to exclude ocular media opacity, were all performed at our ophthalmology department. For pupillary dilatation Tropicamide 1\% eye drops were used and repeated after 10 minutes. After full dilatation, indirect non-contact lens $(+90,+78)$ on slit lamp biomicroscopy were used to grade the retinopathy. KOWA fundus camera (JAPAN VX-10) was used for posterior segment photography. Macular analysis were obtained using Optical Coherence Tomography (OCT) (ZEISS HD 5000 OCT system) to document macular edema detected on clinical examination, identify the type of edema, and measure macular thickness.

DR was classified according to the following grading system: grade 0: no diabetic retinopathy, grade 1: background retinopathy, grade 2: clinically significant macular edema, grade 3: proliferative retinopathy, and grade 4: advanced retinopathy (15).

Statistical analysis: The statistical package of social science SPSS V22 was employed in statistical analysis of the study. Descriptive statistics were presented using frequency distribution table, while Chi square test used to find out associations between studied variables and occurrence of retinopathies. The discrimination point of significance was considered as P-value $<0.05$.

\section{Results}

Of the 386 patients, 109 had retinopathy and the remaining 277 were controls. There was relative female preponderance in both groups with a female to male ratio of 1.31:1 in retinopathy group and 1.16:1 in control group. Most of the patients in both groups were above 40 years. The duration of disease less than ten years in retinopathy group contributed to one quarter (26.6\%) in comparison to nearly two thirds in control group (60.6\%). About one quarter of patients with retinopathy (26.6\%) had BMI less than 25 while only $15.9 \%$ in control group. Most of patients were on oral anti-diabetes drugs in both retinopathy group and control group $(83.5 \%, 89.2 \%$ respectively) as illustrated in table- 1 . 
Table 1: Socio-demographic characteristics of diabetic retinopathy group and control group

\begin{tabular}{lllll}
\hline Characteristics & Categories & $\begin{array}{l}\text { Retinopathy No. } \\
(\%)\end{array}$ & $\begin{array}{l}\text { No retinopathy No. } \\
(\%)\end{array}$ & $\begin{array}{l}\text { Total } \\
\text { No. }(\%)\end{array}$ \\
\hline Gender & Female & $62(56.9)$ & $149(53.8)$ & $211(54.7)$ \\
& Male & $47(43.1)$ & $128(46.2)$ & $175(45.3)$ \\
Age groups (years) & $\leq 40$ & $2(1.8)$ & $18(6.5)$ & $20(5.2)$ \\
& $41-59$ & $75(68.8)$ & $163(58.8)$ & $238(61.6)$ \\
& $\geq 60$ & $32(29.4)$ & $96(34.7)$ & $128(33.2)$ \\
Duration of disease (years) & $<10$ & $29(26.6)$ & $168(60.6)$ & $197(51)$ \\
& $10-19$ & $64(58.7)$ & $99(35.8)$ & $163(42.2)$ \\
BMI $\left(\mathrm{kg} / \mathrm{m}^{2}\right)$ & $\geq 20$ & $16(14.7)$ & $10(3.6)$ & $26(6.8)$ \\
& $<25$ & $29(26.6)$ & $44(15.9)$ & $73(18.9)$ \\
& $25-29.9$ & $42(38.5)$ & $118(42.6)$ & $160(41.5)$ \\
Treatment modality & $\geq 30$ & $38(34.9)$ & $115(41.5)$ & $153(39.6)$ \\
& Oral & $91(83.5)$ & $247(89.2)$ & $338(87.5)$ \\
& Mixed & $13(11.9)$ & $15(5.4)$ & $28(7.3)$ \\
\hline
\end{tabular}

$\mathrm{BMI}=$ body mass index

Table 2 shows a highly significant association between longer duration of disease and retinopathy (P-value 0.0001 ), while age and gender revealed no association with retinopathy.

Table 2: Association between socio-demographic variables and retinopathy

\begin{tabular}{lllll}
\hline Characteristics & Categories & $\begin{array}{l}\text { Retinopathy No. } \\
(\%)\end{array}$ & $\begin{array}{l}\text { No retinopathy } \\
(\%)\end{array}$ & No. P value \\
\hline Duration of disease(years) & $<10$ & $29(26.6)$ & $168(60.6)$ & $0.0001^{* *}$ \\
& $10-19$ & $64(58.7)$ & $99(35.8)$ & $10(3.6)$ \\
Gender & $\geq 20$ & $16(14.7)$ & $149(53.8)$ & 0.58 \\
Age groups (years) & Female & $62(56.9)$ & $128(46.2)$ & 0.074 \\
& $\leq 40$ & $47(43.1)$ & $18(6.5)$ & $163(58.8)$ \\
\end{tabular}

$* *=$ highly significant relationship.

No association was found between BMI and treatment modality with retinopathy as illustrated in table 3.

Table 3: Association between clinical variables and retinopathy

\begin{tabular}{lllll}
\hline Characteristics & Categories & $\begin{array}{l}\text { Retinopathy } \\
\text { No. }(\%)\end{array}$ & $\begin{array}{l}\text { No retinopathy } \\
\text { No. }(\%)\end{array}$ & P value \\
\hline BMI $(\mathrm{kg} / \mathrm{m} 2)$ & $<25$ & $29(26.6)$ & $44(15.9)$ & 0.051 \\
& $25-29.9$ & $42(38.5)$ & $118(42.6)$ & \\
Treatment modality & $\geq 30$ & $38(34.9)$ & $115(41.5)$ & 0.084 \\
& Oral & $91(83.5)$ & $247(89.2)$ & $15(5.4)$ \\
& Mixed & $13(11.9)$ & $15(5.4)$ & \\
\hline
\end{tabular}

$\mathrm{BMI}=$ body mass index

The association between participants' laboratory findings and retinopathy is presented in table 4. Poor glycemic control in contrast to dyslipidemia showed a significant association with a P-value of 0.033 . 
Table 4: Association between laboratory findings and retinopathy

\begin{tabular}{|c|c|c|c|c|}
\hline Characteristics & Categories & $\begin{array}{l}\text { Retinopathy No. } \\
(\%)\end{array}$ & $\begin{array}{l}\text { No retinopathy No. } \\
(\%)\end{array}$ & $P$ value \\
\hline \multirow[t]{3}{*}{ HbA1c (\%) } & $<7$ & $3(2.8)$ & $20(7.2)$ & $0.033 *$ \\
\hline & $7-9$ & $17(15.6)$ & $66(23.8)$ & \\
\hline & $>9$ & $89(81.7)$ & $191(68.9)$ & \\
\hline \multirow[t]{2}{*}{$\mathrm{TG}(\mathrm{mmol} / \mathrm{L})$} & $<1.7$ & $37(33.9)$ & $94(33.9)$ & 0.99 \\
\hline & $\geq 1.7$ & $72(66.1)$ & $183(66.1)$ & \\
\hline \multirow[t]{2}{*}{$\mathrm{TC}(\mathrm{mmol} / \mathrm{L})$} & $<6.2$ & $88(80.7)$ & $232(83.8)$ & 0.48 \\
\hline & $\geq 6.2$ & $21(19.3)$ & $45(16.2)$ & \\
\hline \multirow[t]{2}{*}{ LDL-C (mmol/L) } & $<2.6$ & $28(25.7)$ & $79(28.5)$ & 0.58 \\
\hline & $\geq 2.6$ & $81(74.3)$ & $198(71.5)$ & \\
\hline \multirow[t]{2}{*}{ HDL-C (mmol/L) } & $\geq 1$ & $57(52.3)$ & $133(48)$ & 0.45 \\
\hline & $<1$ & $52(47.7)$ & $144(52)$ & \\
\hline
\end{tabular}

$\mathrm{HbA1c}=$ glycated haemoglobin, $\mathrm{TG}=$ triglyceride, $\mathrm{TC}=$ total cholesterol, LDL-C $=$ low density lipoprotein, HDL-C $=$ height density lipoprotein, $*=$ significant relationship.

\section{Discussion}

We found longer duration of T2DM has strong association with retinopathy (P-value 0.0001) which is supported by most of the reference studies $(7,8,16,17,18)$. This result shows the impact of longer duration of hyperglycemia on the development and progression of DR. However, the duration of the disease is a major risk factor that cannot be modified.

Sadiq H et al (7), Chatziralli IP et al (9), and Stratton et al (19) reported a significant relation between male gender and DR. While Pedro RA et al (20) and Takuya A et al (21) did not find a relation between gender and DR. Our study showed insignificant association between gender and the development of DR (P-value 0.583). Although there was female preponderance in both retinopathy and control groups in our study, the difference between genders was statistically insignificant.

The majority of patients in both DR and control groups were between 41 to 60 years accounting for $61.65 \%$ of the total number of participants. In this study we did not find a significant association between age and DR (Pvalue 0.059$)$, which is similar to other studies $(6,7,8,16,19,22)$. In contrast to our study, Razia A. Ahmed et al (12) and Stratton et al (19) observed a positive relation between age and DR.

Weight disorder is a common problem in T2DM with having an impact on disease management and incidence of complications. Takuya A. et al (21) and V. Narendran et al (24) observed a negative association between BMI and DR while the relation was inconclusive by Cheung N. et al (23). In our study nearly significant relation (P-value 0.51) was found between BMI and DR. Similar result were observed by other Iraqi and UAE studies $(25,22)$.

Various diabetes treatment modalities (oral, insulin, and mixed) were also evaluated in this study. Insulin therapy was significantly associated with DR in some studies $(7,17,26,27)$. In our study however we did not find a positive association between insulin use and DR (P-value 0.084) likely due to the small percentage of insulin users $(5.18 \%)$ compared to those using oral therapy $(87.56 \%)$.

Poor glycemic control manifested by elevated $\mathrm{HbA1c}$ in $\mathrm{T} 2 \mathrm{DM}$ indicates chronic exposure to hyperglycemia leading to increased risk of complications. In a previous study done in our hospital $78.3 \%$ of patients with T2DM had inadequate glycemic control (28). The Diabetes Control and Complications Trial found a $30-40 \%$ decrease risk of DR for each one percent reduction in HbA1c (29). In our study we showed a positive association between increased HbA1c and DR (P-value 0.033), which is consistent with other studies $(6,7,30$, $31)$. In contrast, non-significant association between $\mathrm{HbAlc}$ and retinopathy was found in an Iranian study which may be related to single measurement of $\mathrm{HbA} 1 \mathrm{c}$ or designing the study around a group of patients with good glycaemic control (17).

Dyslipidemia frequently combine T2DM with variable presentation and the prevalence may reach up to $73 \%$ (33). Multiple studies done in different geographical areas showed diversity in the association between serum lipids and DR. Al-Kharji F et al (3), Sadiq H et al (7), and Rema M et al demonstrated significant association (34). In our study we did not find a significant association between various types of serum lipids and DR. Our results were compatible to Pedro RA et al (20), Takuya A et al (21), Rehab B (15), Wong TY (36), and Tapp RJ et al (37). Furthermore, the anti-lipid fenofibrate found to reduce the progression of DR but did not affect the incidence of retinopathy (32).

\section{Conclusions}

Our study found diabetic retinopathy in type 2 diabetes mellitus significantly associated with longer disease duration and poor glycemic control. We did not detect a significant association between diabetic retinopathy and 
gender, body mass index, age, type of treatment, and dyslipidemia.

\section{Aknowlegment}

We would like to express our thanks to Dr. Naeem Obed who kindly assisted with statistical analyses. We are also grateful to Dr Moayad Al Kaptan (MD) for his proofreading.

\section{References}

1. International Diabetes Federation. IDF diabetes atlas. 8th ed. 2017. http://www.diabetesatlas.org/ across-theglobe.html. Accessed 25 Nov 2019.

2. Ali N Sattar, Hussain A Tufaili. The Prevalence of Retinopathy Among Type 2 Diabetes Mellitus Patients in Al-hindeya City, Karbala, Iraq. JHMN.2018; Vol.55:28-31.

3. AlKharji F, Alshemmeri N, Mehrabi L. Prevalence and risk factors for diabetic retinopathy among Kuwaiti diabetics. Kuwait Med J. 2006;38(3):203-06.

4. Wang FH, Liang YB, Zhang F, Wang JJ, Zhang F, Wei WB, et al. Prevalence of diabetic retinopathy in rural China: the Handan Eye Study. Ophthalmology. 2009;116: 461-67.

5. Xie XW, Xu L, Wang YX, Jonas JB. Prevalence and associated factors of diabetic retinopathy. The Beijing Eye Study 2006. Graefes Arch Clin Exp Ophthalmol. 2008;246:1519-26.

6. Ding J, Wong TY. Current epidemiology of diabetic retinopathy and diabetic macular edema. Curr Diab Rep. 2012;12(4):346-54.

7. Sadiq Hussain, Muhammad Arshad Iqbal, Ameer Ahmad, Ehsan Ullah. Risk factors of retinopathy in type 2 diabetes mellitus at a tertiary care hospital, Bahawalpur Pakistan. Pak J Med Sci. 2013;29(No. 2): 536-39.

8. Joanne W.Y. Yau M, Sophie L. Rogers M, Ryo Kawasaki P, Ecosse L. Lamoureux P, Jonathan W. Kowalski, Toke Bek, et al. Global prevalence and major risk factors of diabetic retinopathy. Diabetes Care. 2012;35(3):556-64.

9. Chatziralli IP, Sergentanis TN, Keryttopoulos P, Nikolaos Vatkalis, Antonis Agorastos, Leonidas Papazisis. Risk factors associated with diabetic retinopathy in patients with diabetes mellitus type 2. BMC Research Notes. 2010;3:153-56.

10. Wang FH, Liang YB, Peng XY, Wang JJ, Zhang F, Wei WB, et al. Risk factors for diabetic retinopathy in a rural Chinese population with type 2 diabetes: the Handan Eye Study. Acta Ophthalmologica. 2011; 89(4):336-43.

11. Zheng Y, Lamoureux EL, Lavanya R, Wu R, KamranIkram, Wang JJ, et al. Prevalence and Risk Factors of Diabetic Retinopathy in Migrant Indians in an Urbanized Society in Asia. Ophthalmology. 2012; 10: 2119 24.

12. Razia A. Ahmed, Shamsun N. Khalil, Mohammad A. A. Al-Qahtani. Diabetic retinopathy and the associated risk factors in diabetes type 2 patients in Abha, Saudi Arabia. J Family Community Med. 2016 Jan-Apr; 23(1): 18-24.

13. World Health Organization. (1995). Physical status: The use and interpretation of anthropometry: Report of a WHO Expert committee. Technical report series 854. Geneva.

14. American diabetes association. Standards of Medical Care in Diabetesd-2019. Diabetes care. Jan 2019; 42(Suplement 1).

15. Alastair K.O., Denniston PLM. Diabetic eye disease. Oxford handbook of Ophthalmology. 2014; 3rd $\operatorname{Ed}(13): 534$.

16. RL Thomas, SD Luzio, S Roy Chowdury, SL Hale, RV North, RL Gibbins, et al. Incidence of diabetic retinopathy in people with type 2 diabetes mellitus attending the Diabetic Retinopathy Screening Service for Wales: retrospective analysis. BMJ ophthalmology. Fberuary 2012;344:e874-84.

17. MA Javadi, M Katibeh, N Rafati, MH Dehghan, F Zayeri, M Yaseri, et al. Prevalence of diabetic retinopathy in Tehran province: a population-based study. BMC Ophthalmology. October 2009;9:12-19.

18. Donald S. Fong M, Lloyd Aiello, Thomas W. Gardner, George L. King, George Blankenship, Jerry D. Cavallerano O, et al. Retinopathy in Diabetes. diabetes Care. January 2007;27(Suplement 1).

19. Stratton IM, Kohner EM, Aldington SJ. UKPDS 50: Risk factors for incidence and progression of retinopathy in type 2 diabetes over 6 years from diagnosis. Diabetologia. 2001;44(2):156-63.

20. Pedro RA, Raul NG, Aida VM, Ramon SA, Antonio MR, Nuria S. Differences in incidence of diabetic retinopathy between type 1 and 2 diabetes mellitus: a nine-year follow-up study. Br J Ophthalmol. 2017;101:1346-51.

21. Takuya A, Kiyoaki I, Susumu K, Tomoko O, Masaki W, Kouichi I, et al. A Common Polymorphism in the 5-Untranslated Region of the VEGF Gene Is Associated With Diabetic Retinopathy in Type 2 Diabetes. Diabetes. MAY 2002; 51: 1635-39.

22. Fatma Al- Maskari, El-Sadig M. Prevalence of diabetic retinopathy in the United Arab Emirates; A crosssectional study. BMC ophthalmology. 16 June 2007;7:11-18. 
23. Cheung N, Wong TY. Obesity and eye diseases. Surv Ophthalmol. 2007;52:180-95.

24. V Narendran, RK John, A Raghuram, RD Ravindran, PK Nirmalan, RD Thulasiraj. Diabetic retinopathy among self reported diabetics in southern India: a population based assessment. British Journal of ophthalmology. 2018;11:1136.

25. Ala S Tawfeeq. Prevalence and risk factors of diabetic retinopathy among Iraqi patients with type 2 diabetes mellitus. Iraqi J Com Med. Jan 2015;1:17-21.

26. Rajab AY. Frequency of diabetic retinopathy in Mosul. Annals of the College of Medicine. 2008;34(No.2): 129-34.

27. Raman R, Rani PK, Reddi RS, Gnanamoorthy P, Uthra S, Kumaramanickavel G, et al. Prevalence of diabetic retinopathy in India: Sankara Nethralaya Diabetic Retinopathy Epidemiology and Molecular Genetics Study report 2. Ophthalmology. 2009;116(2):311-18.

28. Ali N. Sattar. The Adequateness of Glycemic Control in Type 2 Diabetes Mellitus. MJB. 2015; 12(4):1129 36.

29. Early worsening of diabetic retinopathy in the Diabetes Control and Complications Trial. Arch Ophthalmol. 1998;116:874-86.

30. El-Bab MF, Shawky N, Al-Sisi A, Akhtar M. Retinopathy and risk factors in diabetic patients from AlMadinah Al-Munawarah in the Kingdom of Saudi Arabia. Clin Ophthalmol. 2012;6:269-76. [PMC free article] [PubMed] [Google Scholar]

31. Al Ghamdi AH, Rabiu M, Hajar S, Yorston D, Kuper H, Polack S. Rapid assessment of avoidable blindness and diabetic retinopathy in Taif, Saudi Arabia. Br J Ophthalmol. 2012;96:1168-72. [PubMed] [Google Scholar]

32. Chew EY, Ambrosius WT, Davis MD, Danis RP, Gangaputra S, Greven CM, et al. Effect of medical therapies on retinopathy progression in type 2 diabetes. N Engl J Med. 2010 363:233-44.

33. Ali N. Sattar. Dyslipidemia: A Frequently Missed Disorder in Type 2 Diabetes Mellitus. JNSR. 2015; 5(22): 14-19.

34. Rema M, Srivastava BK, Anitha B, Deepa R, Mohan V. Association of serum lipids with diabetic retinopathy in urban South Indians - the ChennaiUrban Rural Epidemiology Study (CURES) Eye Study-2. Diabet Med. 2006;23:1029-36.

35. Rehab Benarous, Muhammad BS, Salmaan Qureshi, Eva Fenwick, Mohamed Dirani, Tien YW, et al. Differential Association Of Serum Lipids With Diabetic Retinopathy and Diabetic Macular Edema. investigative Ophthalmology and visual Science. September 2011;52(10 ): 7464-69.

36. Wong TY, Klein R, Islam FM, Cotch MF, Folsom AR, Klein BE, et al. Diabetic retinopathy in a multiethnic cohort in the United States. Am J Ophthalmol. 2006;141:446-55.

37. Tapp RJ, Shaw JE, Harper CA, De Courten MP, Balkau B, McCarty DJ, et al. The prevalence of and factors associated with diabetic retinopathy in the Australian population. Diabetes Care. 2003;26(6):1731-37. 